\title{
Conditions associated with Clostridium sporogenes growth as a surrogate for Clostridium botulinum in nonthermally processed canned butter
}

\author{
R. H. Taylor, ${ }^{*}$ M. L. Dunn, $\dagger$ L. V. Ogden, $†$ L. K. Jefferies, $†$ D. L. Eggett, $\ddagger$ and F. M. Steele ${ }^{1}$ \\ ${ }^{*}$ General Mills, 9000 Plymouth Ave. North, Minneapolis, MN 55427 \\ †Department of Nutrition, Dietetics and Food Science, and \\ ‡Department of Statistics, Brigham Young University, Provo, UT 84602
}

\section{ABSTRACT}

The objective of this study was to better understand the effect of butter composition and emulsion structure on growth and survival of Clostridium sporogenes, used as a surrogate for $C$. botulinum in canned butter. The lack of a thermal process step in commercially available canned butter raises questions of potential safety, because it is hermetically sealed and generally exhibits anaerobic growth conditions, which are optimal for Clostridium botulinum growth. Without thermal processing, low-acid canned foods must have inhibitory factors present to prevent $C$. botulinum growth. Some potential intrinsic inhibitory factors, or hurdles, within butter include: reduced water activity, acidity in cultured products, elevated salt content, and the microdroplet nature of the aqueous phase in the butter emulsion. It was hypothesized that a normal, intact butter emulsion would have sufficient hurdles to prevent $C$. botulinum growth, whereas a broken butter emulsion would result in a coalesced aqueous phase that would allow for $C$. botulinum growth. Batch-churned butter was inoculated with $C$. sporogenes; butter samples with varying salt contents $(0,0.8,1.6$, and $2.4 \%$ wt/ wt $\mathrm{NaCl}$ ) were prepared and stored in coated steel cans for varying times (1 or $2 \mathrm{wk}$ ) and temperatures (22 or $41^{\circ} \mathrm{C}$ ) to determine temperature and emulsion structure effects on C. sporogenes growth. Samples stored at $41^{\circ} \mathrm{C}$ showed a significant increase in $C$. sporogenes growth compared with those stored at $22^{\circ} \mathrm{C}$. Furthermore, $\mathrm{NaCl}$ addition was found to have a significant effect on C. sporogenes growth, with $0.8 \% \mathrm{NaCl}$ promoting more growth than $0 \%$, but with decreases in growth observed at 1.6 and $2.4 \%$. Uninoculated control plates were also found to have bacterial growth; this growth was attributed to other anaerobic bacteria present within the cream. It was concluded that removal of the hurdle created by the micro-droplet size of the emulsion aque-

Received September 27, 2012.

Accepted January 7, 2013.

${ }^{1}$ Corresponding author: frost_steele@byu.edu ous phase could result in $C$. botulinum growth even at elevated salt levels and, therefore, home preparation of canned butter is not advisable. It is also possible that commercially canned butter, if heat abused, could potentially allow for $C$. botulinum growth and, therefore, consumption is not recommended.

Key words: canned butter, Clostridium botulinum, Clostridium sporogenes

\section{INTRODUCTION}

The primary lipid sources currently used in emergency food storage rations include oils and shortenings in liquid or powder form. Both liquid and powdered oils and shortenings have moderate shelf stability; however, both have limitations in versatility of application. Shortenings and oils are typically used in baking or frying applications, or need some preparation before consumption. However, butter can be consumed directly without added preparation, for example on crackers or bread, thereby increasing the palatability of other products with minimal preparation. Therefore, canned butter provides a lipid source with increased versatility of application compared with other lipid products.

The potential benefits and applications of canned butter are evident; however, safety concerns associated with canned butter exist. The National Center for Home Food Preservation has addressed some of these concerns on their website, indicating that most proposed processes for storing canned butter would not prevent growth of Clostridium botulinum and other pathogens in butter stored at room temperature (Andress and Nummer, 2006).

The primary safety concern with canned butter is the potential for growth of $C$. botulinum spores and subsequent toxin production. Processing requirements to inhibit $C$. botulinum growth in canned goods differ depending upon the nature of the food product. Canned butter fits the criteria for a low-acid canned food, which the US Food and Drug Administration defines as any food, other than alcoholic beverages, with a $\mathrm{pH}>4.6$ and water activity $>0.85$, excluding tomatoes 
and tomato products with a finished equilibrium $\mathrm{pH}$ $<4.7$ (Cole and Oh, 2003; FDA, 2010). Canned butter exhibits the above characteristics in an anaerobic storage environment, therefore thermal processing or some other combination of inhibitory factors is required to prevent C. botulinum growth (Cole and Oh, 2003).

In many instances, it is possible to use a combination of nonthermal environmental and compositional parameters to ensure safe production of food products in the event thermal processing will damage the desired finished product. Hurdle technology is the principle of utilizing various conditions within a food product that can act in combination to prevent microbial growth and preserve product quality (Leistner and Gorris, 1995; Leistner, 2000).

In addition to environmental factors, such as temperature and oxygen content, bacterial growth in butter is affected by a variety of intrinsic factors, including acidity $(\mathrm{pH})$, water activity $\left(\mathbf{a}_{\mathrm{w}}\right), \mathrm{NaCl}$ concentration, and butter emulsion structure. Butter is an emulsion that is comprised of a continuous lipid phase with noncontinuous aqueous droplets, containing water-soluble solutes suspended throughout (Fennema, 1996; Charley and Weaver, 1998). The structure of these aqueous droplets affects the microbial stability of the butter product due to the fact that microbial growth within waterin-oil emulsions is confined within the small aqueous droplets, which provide little physical space for growth (Wilson et al., 2002). It has been demonstrated that aqueous droplets $<20 \mu \mathrm{m}$ are inhibitory to bacterial growth (Wehr and Frank, 2004). Properly prepared butter should have less than $5 \%$ of water droplets with diameters larger than $10 \mu \mathrm{m}$ (Lund et al., 2000).

If butter undergoes heat abuse, the water droplets can coalesce to form a much larger aqueous phase. This larger aqueous phase provides a more suitable environment for microbial growth. Verrips and Zaalberg (1980) and Verrips et al. (1980) demonstrated that control of microbial growth in butter is related to the prevention of coalescence of aqueous droplets. Therefore, heat abuse, resulting in breaking of the emulsion structure, can remove one of the inhibitory hurdles and provide an environment more suitable for microbial growth.

Potentially the combination and interaction of the intrinsic factors mentioned above $\left(\mathrm{pH}, \mathrm{a}_{\mathrm{w}}, \mathrm{NaCl}\right.$ concentration, and butter structure) could inhibit bacterial growth in canned butter. Each of these intrinsic factors has cutoff points beyond which $C$. botulinum can no longer grow and where spore growth is inhibited (Table 1). Group I C. botulinum is strongly inhibited below $\mathrm{pH} 4.6$, below $\mathrm{a}_{\mathrm{w}}$ of 0.94 , and at sodium chloride concentrations above $10 \%$ (Simjee, 2007). With respect to emulsion droplet size, it has been shown that bacterial
Table 1. Initial hurdle measurements in commercially canned butter and inhibition threshold for Clostridium botulinum

\begin{tabular}{lcc}
\hline Hurdle in canned butter & $\begin{array}{c}\text { Initial } \\
\text { value }\end{array}$ & $\begin{array}{c}\text { Inhibition } \\
\text { threshold }\end{array}$ \\
\hline pH & $6.06 \pm 0.14$ & $<4.6^{1}$ \\
Water activity & $0.94 \pm 0.007$ & $<0.94^{1}$ \\
Aqueous NaCl $(\%)$ & $9.26 \pm 0.55$ & $>10^{1}$ \\
Aqueous droplet diameter $(\mu \mathrm{m})$ & $5.46 \pm 0.30$ & $<20^{2}$ \\
\hline
\end{tabular}

${ }^{1}$ Simjee (2007).

${ }^{2}$ Wehr and Frank (2004).

growth is limited when aqueous droplet diameters are less than $20 \mu \mathrm{m}$ (Wehr and Frank, 2004).

Previously published typical values for butter (Voysey et al., 2009), corroborated by our own preliminary results, indicate that levels for many of these intrinsic factors were near the limit for C. botulinum growth, but all were still within ranges that would allow for C. botulinum growth. It is possible that, even though these intrinsic factors are individually not at levels that would inhibit $C$. botulinum growth, these suboptimal intrinsic factors could produce a combined inhibitory effect against $C$. botulinum.

If, in fact, these 4 intrinsic factors do combine to inhibit growth of $C$. botulinum, the consequences of removing even one of these hurdles could be reason for concern. For example, commercially canned butter, stored in a cool environment, would likely maintain intact emulsion structure; however, the same butter stored in a hot warehouse or other location with fluctuating temperatures, would almost certainly break down and lose its structure, resulting in coalescence of dispersed droplets and separation of the aqueous and lipid phases. Likewise, current methods described online for canning butter in a home environment involve heating the butter, which results in a separation of phases and damage of the butter emulsion structure. The inhibitory hurdle created by small aqueous droplet size would thus be eliminated.

The objective of this study was to better understand the effect of butter composition and structure on growth and survival of Clostridium sporogenes, used as a surrogate for $C$. botulinum in canned butter. Clostridium sporogenes shares a close DNA homology with C. botulinum and has been used extensively as a surrogate in previous thermal process studies (Mah et al., 2008; Bull et al., 2009). Experimental parameters were designed to evaluate the effects of altered butter emulsion structure and varying salt content on overall survival and growth of $C$. sporogenes in traditional noncultured butter. This design allows for determination of the microbial safety of canned butter and an increased understanding of 
parameters affecting $C$. botulinum outgrowth and toxin production.

\section{MATERIALS AND METHODS}

\section{Growth and Purification of C. sporogenes Spores}

Spore Growth and Purification. Clostridium sporogenes strain NCA 3679 was purchased from the American Type Culture Collection (ATCC; Manassas, VA). Lyophilized C. sporogenes was reanimated as described on the product information sheet for the strain (ATCC \#7955). Completion of sporulation was determined by phase contrast microscopy and classified as the point at which sporulation had reached $90 \%$ or greater (Yang et al., 2009).

Upon completion of sporulation, purification of the spores was performed as described by Yang et al. (2009). The purified spores were transferred into 2-mL cryovials and stored at $4^{\circ} \mathrm{C}$.

Determination of Spore Counts and Spore Culturability. A hemocytometer was used to determine the count of the purified C. sporogenes spores. Dilutions $\left(10^{-2}, 10^{-3}\right.$, and $\left.10^{-4}\right)$ of purified spore samples were made and analyzed on a phase-contrast microscope as described by Yang et al. (2009). To determine spore culturability, duplicate spore samples were diluted and plated on reinforced clostridial agar (RCA; Hirsch and Grinstead, 1954; Becton Dickinson and Co., Sparks, $\mathrm{MD})$. The plates were incubated anaerobically at $37^{\circ} \mathrm{C}$ for $72 \mathrm{~h}$ (Nygaard and Hostmark, 2008); plate counts were determined following incubation.

\section{Anaerobic Incubation}

Anaerobic incubation conditions were created using a sealed incubator with a vacuum pump attached. This allowed removal of ambient air from the chamber and subsequent flushing of the chamber with an anaerobic gas mixture $\left(90 \% \mathrm{~N}_{2}, 5 \% \mathrm{CO}_{2}, 5 \% \mathrm{H}_{2}\right)$. Palladium catalyst (Sigma-Aldrich, St. Louis, MO) was placed in a culture dish in the incubator as an oxygen scavenger. Drierite dessicant (W.A. Hammond Drierite Co., Xenia, $\mathrm{OH}$ ) was placed in the incubator to control excess moisture. The plates were placed in the incubator and the chamber ambient air was removed by vacuum pump. The chamber was then flushed with the anaerobic gas mixture 3 times. Anaerobic indicator strips (BR0055B, Oxoid Ltd., Basingstoke, UK) were used to confirm anaerobic conditions.

\section{Batch Churn Butter Production}

Butter was produced by a batch-churn process using pasteurized cream provided by Deseret Dairy (Salt Lake
City, UT); the butter was produced using a method adapted from Wood et al. (1975) and Britten et al. (2008). The cream was transported from Deseret Dairy and stored at $4^{\circ} \mathrm{C}$; prior to churning, the cream was allowed to warm slightly until it reached a temperature of 6 to $9^{\circ} \mathrm{C}$. The cream was churned to butter using a Hobart A120T mixer (Hobart Corp., Troy, OH). All bowls, attachments, and instruments used during the butter making process were autoclaved before use to minimize potential for contamination. The cream was mixed with the whisk attachment for 1 min on setting 2 and then for 5 to $7 \mathrm{~min}$ on setting 3 (until the emulsion broke). Once the emulsion was broken and the cream separated into butter and buttermilk fractions, the buttermilk fraction was discarded. The remaining butter fraction was then mixed using the beater attachment for $30 \mathrm{~s}$ on setting 1 to remove any remaining buttermilk from the solid butter fraction. The butter was then washed 3 to 4 times by adding $250 \mathrm{~mL}$ of chilled, autoclaved, distilled water and mixing with the beater attachment. The wash residue was discarded each time and washing was repeated until the wash residue was clear. After the final wash step, the butter was pressed together using cheese cloth to extract excess moisture present in the butter.

To simulate cream contaminated with $C$. botulinum, cream was inoculated with purified $C$. sporogenes spores at a concentration of $3.0 \times 10^{4} \mathrm{cfu} / \mathrm{mL}$. After inoculation, the cream was churned to butter following the protocol described above. The only process change for inoculated samples involved added precautions taken to ensure proper collection and disposal of by-products produced during the production of inoculated samples.

\section{Salt Incorporation}

Following butter formation, salt was incorporated into the butter product. Morton iodized table salt (Morton, Chicago, IL) was finely ground using a coffee grinder (Hamilton Beach/Proctor-Silex Inc., Washington, NC) and dried at $100^{\circ} \mathrm{C}$ overnight. Dried salt was kept in sealed bottles in a desiccator before use. After batch formation, the butter was separated into four $375-\mathrm{g}$ fractions and different salt amounts were added to each to create 4 salt variables: $0(0 \%), 3.0(0.8 \%)$, $6.0(1.6 \%)$, and $9.0 \mathrm{~g}(2.4 \%)$.

\section{Flushing, Canning, and Storage of Butter}

Following salt addition, butter samples were placed into a sanitized No. 300 can coated with universal enamel. Care was taken to ensure butter samples were pressed down into the can to eliminate any air present. The can was flushed with $\mathrm{N}_{2}$ gas and sealed with 
a ZPT-30J Ageless oxygen absorber (Mitsubishi Gas Chemical America, New York, NY) taped on the inside to help ensure an anaerobic environment. Cans were stored at either $22 \pm 2^{\circ} \mathrm{C}$ or $41 \pm 2^{\circ} \mathrm{C}$, with the higher temperature selected to result in emulsion phase separation, a worst-case scenario for butter structure.

\section{Experimental Design}

Cans from each batch of inoculated or uninoculated churned butter were randomly assigned to each treatment [\% $\mathrm{NaCl}, 4$ levels $(0,0.8,1.6$, and $2.4 \%)$; storage temperature, 2 levels $\left(22\right.$ and $\left.41^{\circ} \mathrm{C}\right)$; storage time, 2 levels $(1$ and $2 \mathrm{wk})]$ in a randomized block design with full factorial assignment of treatments with appropriate controls. The entire experimental design was performed in duplicate.

\section{Sampling, Dilutions, and Plating of C. sporogenes}

Sample Collection. Sampling of the butter product was performed as described in section 3.073 of Standard Methods for the Examination of Dairy Products (SMEDP; Wehr and Frank, 2004). The described method was adapted for sampling product from a No. 300 can. For $22^{\circ} \mathrm{C}$ samples, a sterile, stainless steel spatula was used to remove a plug of butter the length of the can, and the butter sample was placed in a 50-mL conical tube. Sampling was repeated at approximately 3 locations within the can until a $20-\mathrm{g}$ sample was obtained. The samples stored at $41^{\circ} \mathrm{C}$ had separate aqueous and lipid fractions, therefore the samples were mixed with a sterile stainless steel spatula to collect a representative sample. After mixing the 2 phases, a 20-g sample was poured into a 50-mL conical tube.

Sample Dilution. Dilutions were performed according to protocol 9.060 in SMEDP (Wehr and Frank, 2004). In the standard method, 99-mL dilution blanks are used, however, 9-mL dilution tubes with autoclaved $0.1 \%$ peptone were used for this study. Dilutions prepared for $22^{\circ} \mathrm{C}$ stored samples were $10^{-1}$ and $10^{-2}$, whereas dilutions for $41^{\circ} \mathrm{C}$ stored samples were $10^{-1}, 10^{-2}, 10^{-3}, 10^{-4}$, and $10^{-5}$. The specified dilutions for each temperature variable were based on expected growth counts as determined by preliminary experiments.

Plating and Incubation. Samples were plated using the spread plate technique, in which a sample pipetted onto the prepared plate is spread over the surface of the RCA plates using a sterile bent glass rod. To plate a $10^{-1}$ final dilution, $1 \mathrm{~mL}$ of a $10^{-1}$ sample dilution tube was distributed across 3 separate plates. Following anaerobic incubation at $37^{\circ} \mathrm{C}$ for $72 \mathrm{~h}$, the colonies on the 3 plates were counted and the total colonies of the 3 plates were combined. Then $100-\mu \mathrm{L}$ aliquots from the $10^{-1}$ to $10^{-5}$ dilutions were plated on RCA to achieve final plate dilutions from $10^{-2}$ to $10^{-6}$, respectively. All dilutions were plated in duplicate and plates were incubated under anaerobic conditions.

\section{Confirmation of C. sporogenes Colony Growth}

Reinforced clostridial agar plates containing purified C. sporogenes spores from the original ATCC-type culture and RCA plates with presumed C. sporogenes colonies from inoculated butter samples were analyzed by Microbial Identification Inc. (MIDI; Newark, NJ) analysis. Representative colonies with colony morphology similarities to C. sporogenes, and also different from C. sporogenes morphology, were isolated for confirmation of identity. The identification of isolated colonies was conducted by the Microbial Identification System (MIS), which evaluates the whole cell-FA profile using GC (MIDI Inc.). Extractions of FA methyl esters from colony samples were performed according to MIDI instructions, and were analyzed on a 6890 Series Gas Chromatograph (Agilent Technologies, Santa Clara, CA) using the MIDI MIS software (MIDI Inc.; Slabbinck et al., 2008; Yilmaz, 2009).

\section{Emulsion Stability Determination: Confocal Microscopy}

Slides were prepared using a method adapted from Van Dalen (2002). An updated method was provided by Han Blonk (Unilever NV, Rotterdam, the Netherlands) through personal communication. Nile Red dye crystals (N3010, Sigma-Aldrich) were placed on a clean microscope slide; a sample of the butter product was taken using a sterile stainless steel spatula and the butter sample was placed on top of the crystals on the slide. A coverslip was placed on the butter and the butter was pressed flat with the coverslip, ensuring the thickness of the butter was maintained at $1 \mathrm{~mm}$. The samples were then placed in a foil-covered container to exclude light and stored at $4^{\circ} \mathrm{C}$ for $48 \mathrm{~h}$ to allow dye penetration throughout the lipid phase of the sample. The samples were analyzed by confocal microscopy to determine overall droplet size.

The Olympus FluoView FV 300 confocal laser scanning microscope (Olympus America Inc., PA) with FluoView software was used for image generation with the following settings: laser $=\mathrm{He}-\mathrm{Ne}$ Green 543, dye $=$ Trit $\mathrm{C}$, Kalman setting $=3$. The $40 \times$ objective was used for all sample images, and Z-stack images were taken to obtain images at varying depths throughout the butter. 
Quantitative analysis of slide data was performed using ImageJ software (Abramoff et al., 2004). ImageJ software was used to count the number of aqueous droplets and determine the average area of the aqueous droplets. Image scale was set based on the $50-\mu \mathrm{m}$ measure bar for each image. Images were converted to binary 8-bit images and adjustments were made to brightness and contrast as well as image threshold values to ensure optimal image resolution. Droplets with an area $<2 \mu \mathrm{m}^{2}$ based on Image J measurements were excluded to ensure black pixels that may or may not be actual droplets were rejected; acceptable droplets had an area $\geq 2 \mu \mathrm{m}^{2}$. Total droplet number as well as average droplet area data was collected for each image. Statistically, mean droplet diameter for batch and continuous processed samples was compared using a $t$-test (one sided; unpaired-equal variance).

\section{Separation of the Aqueous Fraction of Butter}

Separation of the aqueous fraction was adapted from a protocol used by Britten et al. (2008). The butter was placed in a beaker and placed on a hotplate to melt the butter sample. The melted butter sample was transferred to a clean separatory funnel surrounded by hotplates to ensure the sample remained warm enough to prevent solidification of the melted butter. The butter sample was then left in the separatory funnel to allow the aqueous phase to settle to the bottom of the funnel. After the majority of the aqueous phase had settled to the base of the separatory funnel $(\sim 15 \mathrm{~min})$, the aqueous phase was emptied into a sterile $50-\mathrm{mL}$ conical tube. The $50-\mathrm{mL}$ conical tube was then centrifuged at $1,116 \times$ for $10 \mathrm{~min}$ at $21^{\circ} \mathrm{C}$ to separate any residual lipid phase from the aqueous fraction. The lipid layer formed on the top was removed and the aqueous layer was transferred to a sterile $50-\mathrm{mL}$ conical tube using a disposable transfer pipette. The separated aqueous fraction was stored at $4^{\circ} \mathrm{C}$.

\section{Measurement of Potential Hurdles}

Percent $\mathrm{O}_{2}$ Headspace Measurement. Illinois Instruments 6500 headspace oxygen analyzer (Illinois Instruments, Johnsburg, IL) was used to determine percent $\mathrm{O}_{2}$ in the headspace of the canned butter samples. Adhesive septa were placed on the can lid and a can puncture attachment was used to puncture the can for sampling. A sample was removed using a 50$\mathrm{mL}$ syringe, which was then injected into the sample port of the headspace analyzer. Duplicate headspace samples were taken from each can and the percent $\mathrm{O}_{2}$ was recorded. $a_{w}$ Measurement. Water activity of each sample was determined using the Aqua Lab Water Activity Meter Series 3 (Decagon, Pullman, WA). The $\mathrm{a}_{\mathrm{w}}$ was measured following the protocol described in the AquaLab Water Activity Meter operator's manual using sample cups, lids, and verification standards as specified by Decagon.

pH Measurement. Measurement of $\mathrm{pH}$ was performed as described in SMEDP 15.022.9.4.4 (Wehr and Frank, 2004). To determine the $\mathrm{pH}$ value of butter, it was necessary to measure the $\mathrm{pH}$ of the isolated aqueous phase. Therefore, separation and isolation of the aqueous phase (as described above) was performed before $\mathrm{pH}$ measurement. Duplicate butter samples were analyzed for each treatment and average $\mathrm{pH}$ values were recorded.

Percent NaCl Determination. The percent $\mathrm{NaCl}$ was determined using the AOAC method 960.29 (AOAC International, 2003). Samples were analyzed for salt content of the entire butter product as well as for the aqueous fraction of the butter. Samples ( $5 \pm$ $0.01 \mathrm{~g}$ ) were weighed into an Erlenmeyer flask and the weight was recorded. Then, $100 \mathrm{~mL}$ of boiling water was added to each flask to melt the butter sample and the samples were allowed to cool to 50 to $55^{\circ} \mathrm{C}$. Two grams of $\mathrm{K}_{2} \mathrm{CrO}_{4}$ was added to each sample and the samples were titrated with $0.1 \mathrm{M}$ of $\mathrm{AgNO}_{3}$ following the AOAC official method (AOAC International, 2003). Duplicate samples from each can were taken and averaged to obtain the final percent $\mathrm{NaCl}$ of each sample.

\section{Sensory Panel}

Consumer acceptance of butter containing varying salt amounts was evaluated in the Brigham Young University (BYU) Sensory Laboratory to determine the threshold of salt levels that consumers found acceptable. A 53-member consumer panel was recruited from a database of university employees and students with approximately equal representation among age categories from age 20 to 60 years. Approval for use of human subjects was granted by the Institutional Review Board and panelists provided informed consent before participation.

Butter fractions with 5 different added salt percentages $(0.8,1.6,2.4,3.2$, and $4.0 \%)$ were made in the BYU laboratory. Butter production and salt incorporation was performed following the methods described above in the methods section; butter samples for the consumer panel were uninoculated and prepared using good manufacturing practices. Samples were prepared for the consumer panel by placing $2 \mathrm{~g}( \pm 0.2 \mathrm{~g})$ of butter into sample cups labeled with random 3 -digit sample 
blinding codes and lids placed on the sample cups. Samples were prepared the day before the sensory panel and stored at $4^{\circ} \mathrm{C}$ overnight. The samples were removed from the refrigerator and allowed to equilibrate at room temperature $\left(22^{\circ} \mathrm{C}\right) 2 \mathrm{~h}$ before the consumer panel. The 5 samples were presented side-by-side with squares (4 $\times 4 \mathrm{~cm}$ ) of white bread. An unsalted cracker and water were provided to enable panelists to refresh their sense of taste between each sample. Panelists were provided 5 taster spoons and instructed to spread the entire $2-\mathrm{g}$ sample over each respective square of bread using a different taster spoon for each sample.

Questions were presented one at a time on a computer screen and data were collected using Compusense 5 (version 5.2) software (Compusense Inc., Guelph, Ontario, Canada). Panelists evaluated appearance, overall flavor, salt flavor, and overall acceptability using a discrete 9 -point hedonic scale where $9=$ like extremely, $5=$ neither like nor dislike, and $1=$ dislike extremely. Determination of appropriate salt level was done using a just-about-right ideality question, in which $5=$ definitely too high, $3=$ just-about-right, and $1=$ definitely too low. Panelists were also asked to rank the 5 samples in order of preference, with 1 being the most liked and 5 being the least liked. Panelists were instructed to use a bite of unsalted cracker and sip of bottled water to refresh their sense of taste between samples. Panelists were compensated monetarily for their time.

\section{Statistical Analysis}

SAS 2007 (version 9.2) software (SAS Inc., Cary, NC) was used to perform an analysis of covariance (ANCOVA) using initial bacterial counts and headspace as covariates. The ANCOVA was performed on the experimental data to determine what variables had a significant effect on the $C$. sporogenes counts. The reduced model was used for the analysis. Analysis of variance was also performed using SAS with Tukeyadjusted, post-hoc pairwise comparisons to determine the effects of storage temperature and salt content on $\mathrm{pH}$. Bar charts for bacterial counts were generated with XL STAT (version 2008.7.03; Addinsoft, Paris, France). Basic statistical data including means, standard deviations, and $t$-tests were obtained using Microsoft Excel 2010 (Microsoft Corp., Redmond, WA). Ideality statistics were performed based on a method described by Stone (1985).

\section{RESULTS AND DISCUSSION}

\section{Commercial Canned Butter Composition}

Commercial canned butter samples were tested to determine expected values related to the 4 intrinsic hurdles considered $\left(\mathrm{pH}, \mathrm{a}_{\mathrm{w}}, \% \mathrm{NaCl}\right.$, and aqueous droplet diameter). It was observed that values for $\mathrm{pH}$, $\mathrm{a}_{\mathrm{w}}$, and $\% \mathrm{NaCl}$ were within ranges that individually would allow for $C$. botulinum growth (Table 1). However, $\mathrm{a}_{\mathrm{w}}$ was at the cutoff point, and $\mathrm{pH}$ and aqueous percent $\mathrm{NaCl}$ were near the threshold of inhibition; it is possible that the combination of all 4 hurdle values could provide inhibition. The observed average droplet diameter would be inhibitory to C. botulinum; however, whereas the average was within the inhibition threshold, some individual droplets were larger than $20 \mu \mathrm{m}$, which could allow for $C$. botulinum growth. The $<20$ $\mu \mathrm{m}$ inhibition level reported for droplet diameter applies to all bacteria, not just C. botulinum (Wehr and Frank, 2004).

\section{Canned Butter Sample Results}

Anaerobic plate count data were collected for each batch of butter produced. Control batches with no added $C$. sporogenes inoculum resulted in $<10 \mathrm{cfu} / \mathrm{g}$, based on no colonies observed at a $10^{-1}$ dilution. The initial average count, for batches of butter produced with $C$. sporogenes inoculated cream, was $1.2 \times 10^{2} \pm$ $28 \mathrm{cfu} / \mathrm{g}$.

The headspace percent $\mathrm{O}_{2}$ was measured for each can sample and results were generally less than $2 \% \mathrm{O}_{2}$ (data not shown). The $22^{\circ} \mathrm{C}$ stored samples typically had higher percent $\mathrm{O}_{2}$ levels, compared with the $41^{\circ} \mathrm{C}$ stored samples, and the levels of oxygen present seemed to show a correlation with the level of microbial growth within the sample. Therefore, it is likely that the increased temperature conditions allowed for an increase in bacterial growth, which resulted in decreased oxygen levels due to bacterial consumption.

Clostridium sporogenes counts in canned butter after storage under the particular treatment conditions were recorded and results for wk 1 of storage are shown in Figure 1. Sodium chloride addition was found to have a significant effect on C. sporogenes growth, with $0.8 \%$ $\mathrm{NaCl}$ promoting more growth than $0 \%$, but with decreases in growth beyond $0.8 \%$. It was expected that the highest $C$. sporogenes counts would be observed in samples with $0 \% \mathrm{NaCl}$, with the bacterial counts decreasing as $\% \mathrm{NaCl}$ increased. One possible explanation for the higher C. sporogenes counts at $0.8 \%$, compared with $0 \% \mathrm{NaCl}$, could be competitive bacteria present within the sample. It is possible that in the $0 \%$ $\mathrm{NaCl}$ samples, competitive bacteria present within the sample outcompeted $C$. sporogenes; however, as the salt content increased to $0.8 \% \mathrm{NaCl}$, the competitive organisms were inhibited and C. sporogenes counts increased. Clostridium sporogenes counts decreased slightly at $1.6 \%$ and more significantly at $2.4 \%$. Clostridium sporogenes 
Table 2. The $\mathrm{pH}$ values of butter samples with varying salt percentages stored at 22 and $41^{\circ} \mathrm{C}$

\begin{tabular}{lcc}
\hline & \multicolumn{2}{c}{$\mathrm{pH}$} \\
\cline { 2 - 3 } Added & $22^{\circ} \mathrm{C}$ & $41^{\circ} \mathrm{C}$ \\
\cline { 2 - 3 } NaCl $(\%)$ & $6.49 \pm 0.69$ & $4.55 \pm 0.20$ \\
0 & $6.80 \pm 0.13$ & $5.90 \pm 0.33$ \\
0.8 & $6.87 \pm 0.09$ & $5.90 \pm 0.46$ \\
1.6 & $6.74 \pm 0.12$ & $6.13 \pm 0.37$ \\
2.4 &
\end{tabular}

counts at $2.4 \% \mathrm{NaCl}$ were very close to the original inoculation level. The MIDI analysis revealed possible bacterial candidates present within the canned butter samples, including Clostridium oceanicum, Coprococcus eutactus, Fusobacterium rusii, Bifidobacterium breve, and Clostridium cadaveris.

One indication of the growth of competitive bacteria in the $41^{\circ} \mathrm{C}, 0 \% \mathrm{NaCl}$ samples is $\mathrm{pH}$, which was significantly lower in the $41^{\circ} \mathrm{C}, 0 \% \mathrm{NaCl}$ samples compared with all other temperature and salt combinations $(P$ $<0.0001$ ). Table 2 indicates the $\mathrm{pH}$ value obtained with different percentages of $\mathrm{NaCl}$ added. The mean $\mathrm{pH}$ value for the $0 \% \mathrm{NaCl}$ sample incubated at $41^{\circ} \mathrm{C}$ was 4.55 , whereas the mean $\mathrm{pH}$ values for the other salt percentages were closer to original $\mathrm{pH}$ of the butter $(6.06 \pm 0.14$; shown in Table 1$)$. Therefore, it appears as though other bacteria present within the butter samples are outcompeting $C$. sporogenes at $0 \%$ added $\mathrm{NaCl}$ and producing acid as a by-product, which lowers the $\mathrm{pH}$ of the butter and results in decreased $C$. sporogenes counts. However, C. sporogenes appears to be more salt tolerant and is able to outcompete the competitive bacteria at higher salt levels. As mentioned previously, C. sporogenes is able to survive aqueous salt percentages of up to $10 \%$, which corresponds to around $1.6 \%$ added $\mathrm{NaCl}$ (Voysey et al., 2009). Therefore, at $0.8 \%$ added $\mathrm{NaCl}$, C. sporogenes could survive while the competitive bacteria are inhibited, resulting in increased C. sporogenes levels due to the organism's increased salt tolerance.

It was observed that some $C$. sporogenes growth still occurred at the $2.4 \% \mathrm{NaCl}$ added levels. In the majority of samples, high salt concentrations proved inhibitory; however, in some samples $C$. sporogenes survived. Therefore, it is possible that cream contaminated with C. sporogenes and subsequently churned to butter could allow for survival and growth, even at high added salt percentages, due to uneven salt distribution or other factors.

It is noteworthy that titration of the aqueous fraction of the butter showed that actual levels of aqueous percent $\mathrm{NaCl}$ were often lower than target salt addition levels (Table 3). The significantly lower aqueous levels as compared with target levels are likely due to reten-

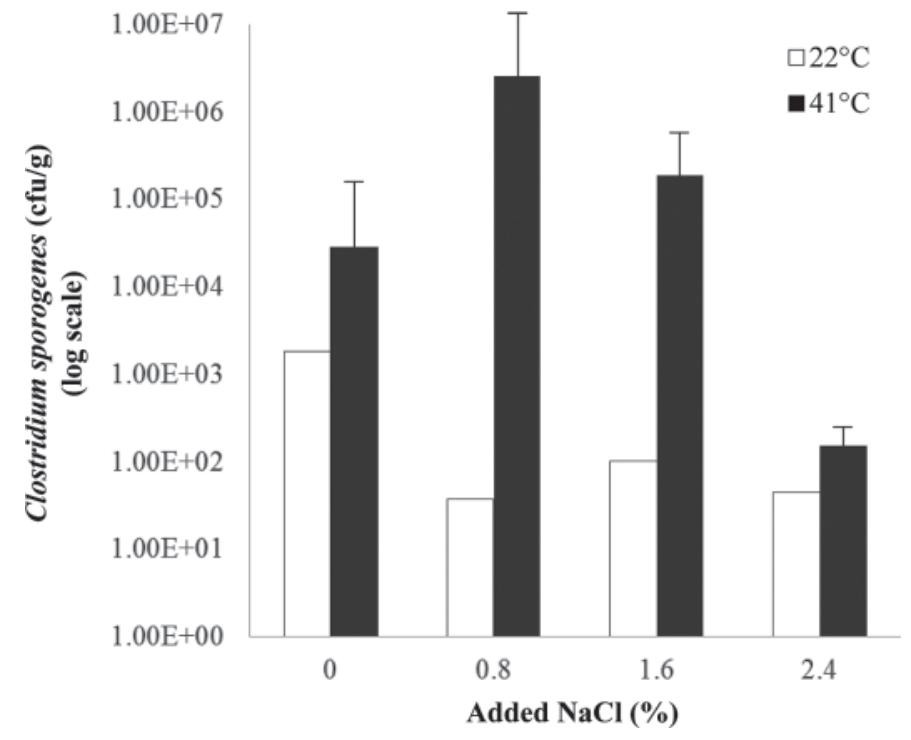

Figure 1. Clostridium sporogenes growth at varying added salt percentages $(0,0.8,1.6$, and $2.4 \%)$ held at 22 and $41^{\circ} \mathrm{C}$ storage for $1 \mathrm{wk}$.

tion of salt in the fat phase, or possibly uneven distribution of the salt in some samples. Therefore, the $C$. sporogenes growth occurring at high salt percentages is potentially due to the fact that the overall level of salt incorporated into the aqueous phase was variable and sometimes not sufficient to be completely inhibitory. In a continuous commercial process these inconsistencies could be corrected through standardized processing and incorporation of salt in a slurry.

\section{Statistical Interactions}

An initial ANOVA was performed to identify confounding variables; potential confounding variables of consideration included percentage $\mathrm{O}_{2}$ headspace, $\mathrm{a}_{\mathrm{w}}$, and $\mathrm{pH}$. Of these potential confounding variables, only percentage $\mathrm{O}_{2}$ headspace exhibited a significant effect on the plate count results $(P=0.03)$. Therefore, $\mathrm{a}_{\mathrm{w}}$ and $\mathrm{pH}$ were eliminated from further analysis. The specific variables that were analyzed in the second step of the ANCOVA were the dependent variables - bacterial plate count and percentage $\mathrm{O}_{2}$ headspace - and the

Table 3. Comparison of percent $\mathrm{NaCl}$ added per total weight of the butter, the target percent $\mathrm{NaCl}$ in the aqueous (Aq) phase, and the actual measured percent $\mathrm{NaCl}$ in the aqueous phase

\begin{tabular}{lcc}
\hline $\begin{array}{l}\text { Added } \\
\mathrm{NaCl}(\%)\end{array}$ & $\begin{array}{c}\text { Target Aq } \\
\mathrm{NaCl}(\%)\end{array}$ & $\begin{array}{c}\text { Actual Aq } \\
\mathrm{NaCl}(\%)\end{array}$ \\
\hline 0 & 0 & $0.16 \pm 0.03$ \\
0.8 & 4 & $3.38 \pm 0.28$ \\
1.6 & 8 & $6.11 \pm 0.77$ \\
2.4 & 12 & $8.98 \pm 0.79$ \\
\hline
\end{tabular}


independent variables: percent $\mathrm{NaCl}(0,0.8,1.6,2.4 \%)$, inoculation status (inoculated with $C$. sporogenes or not), storage temperature $\left(22\right.$ and $\left.41^{\circ} \mathrm{C}\right)$, and storage time ( 1 or $2 \mathrm{wk}$ ), including interactions among any of the factors. It was observed that percent $\mathrm{NaCl}$, storage temperature, and the combination of the 2 had a significant effect on $C$. sporogenes growth with $P$-values of $0.0004,0.0002$, and 0.003 , respectively. It was determined that the length of storage, whether 1 or 2 wk, did not have a significant effect $(P=0.60)$ on $C$. sporogenes growth.

It is of note that whether the samples were inoculated or not did not have a significant effect on the bacterial count $(P=0.75)$. The reason for this is the fact that some of the control samples exhibited growth on the RCA plates. The results of the control sample plating data are shown in Figure 2. Inoculated sample plates contained spherical colonies with a cotton-like appearance, which are typical of $C$. sporogenes (Nygaard and Hostmark, 2008). However, the plates also exhibited additional colony growth beyond the typical $C$. sporogenes colonies, including small, round colonies and colonies with a distinct peak rising out of the center. Definitive identification of these colonies was not achieved; however, some colonies were analyzed by MIDI and potential bacterial species were determined. Some potential species included Clostridium oceanicum, Bifidobacterium breve, Coprococcus eutactus, Clostridium cadaveris, and Clostridium tyrobutyricum.

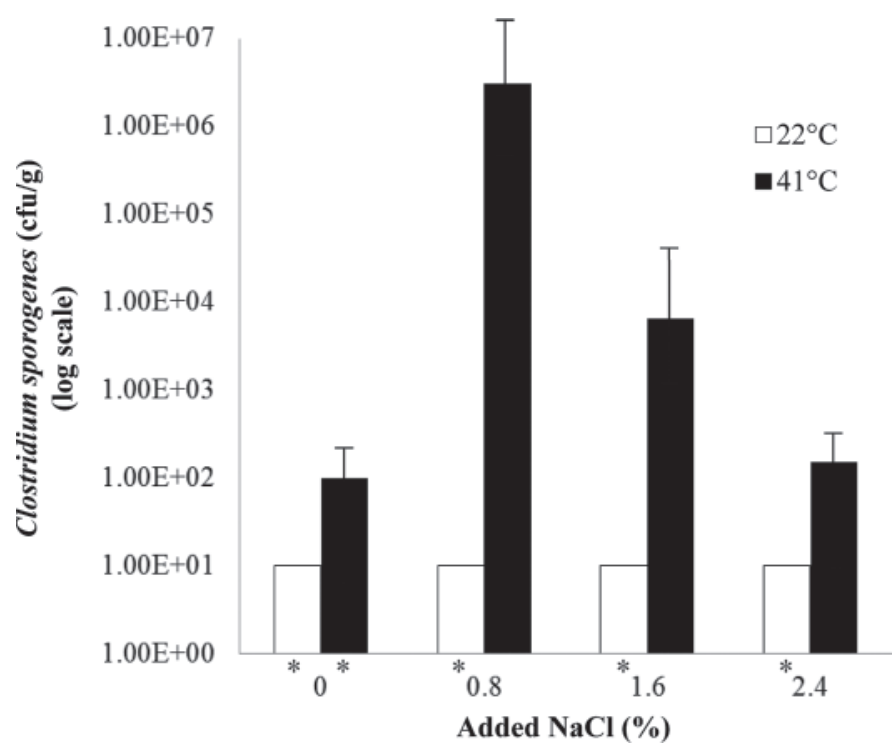

Figure 2. Bacterial growth with colony formation similar to that of Clostridium sporogenes from control (uninoculated) butter samples. Columns marked with an asterisk indicate no growth at the limit of detection based on the dilution plated. Reported values for these columns are $<10 \mathrm{cfu} / \mathrm{g}$ for the $22^{\circ} \mathrm{C}$ samples and $<100 \mathrm{cfu} / \mathrm{g}$ for the $41^{\circ} \mathrm{C}$ sample at $1 \mathrm{wk}$ of storage.
One potential contaminating organism in cream is the bacteria Clostridium tyrobutyricum. This particular bacteria is an anaerobic, lactate-fermenting, sporeformer, which is found in milk products (Dasgupta and Hull, 1989; Klijn et al., 1995; Le Bourhis et al., 2007). Spores of $C$. tyrobutyricum survive pasteurization and cause a defect in cheese known as late blowing (Dasgupta and Hull, 1989). Optimal pH for growth of C. tyrobutyricum is 5.8 (Le Bourhis et al., 2007), which is close to the average $\mathrm{pH}$ values measured for the butter produced in this study. This is one potential bacterial species that may be present within the pasteurized cream; however, further identification procedures, such as 16S rRNA analysis, need to be performed to definitively confirm the presence of $C$. tyrobutyricum or to identify other possible anaerobic bacteria present in butter. The presence of other organisms in the butter also introduces the possibility that another hurdle is present in the system with the competitive inhibition of these organisms naturally present in the cream.

\section{Storage Temperature Effects}

Samples stored at room temperature $\left(22^{\circ} \mathrm{C}\right)$ did not show a large increase in overall $C$. sporogenes growth at any of the salt percentages tested. The levels of $C$. sporogenes remained somewhat constant relative to the initial $C$. sporogenes counts of the butter. It appears that the maintenance of small aqueous droplet size in the butter structure helped limit $C$. sporogenes growth due to limited space or limited nutrient availability. Another factor affecting C. sporogenes growth at room temperature is the fact that the incubation temperature was below the optimal range $\left(35-40^{\circ} \mathrm{C}\right)$ for C. sporogenes growth (Simjee, 2007).

Butter samples stored at $41^{\circ} \mathrm{C}$ for the specified storage period resulted in broken emulsions, and increased C. sporogenes growth was observed, specifically at the lower salt percentages (Figure 1). A significant increase in the number of C. sporogenes colonies at $0.8 \%$ added $\mathrm{NaCl}$ was observed, with decreasing counts as percent $\mathrm{NaCl}$ added increased, as stated previously. It appears that the resulting increase in combined aqueous phase volume in the broken emulsions at $41^{\circ} \mathrm{C}$ provided a suitable environment for $C$. sporogenes growth. Incubation of the samples at $41^{\circ} \mathrm{C}$ also provided an incubation temperature close to the optimal growth temperature for C. sporogenes. Based on the experimental design, it was not possible to differentiate which of the factors (breaking the emulsion or optimal growth temperature) was responsible for the increase in $C$. sporogenes growth. It is likely that both factors play a role and have an effect on overall growth; however to further 
identify which factor may have played a larger role, a small, secondary experiment was performed.

The secondary experiment involved incubating canned butter samples at $41^{\circ} \mathrm{C}$ for $18 \mathrm{~h}$ to break the emulsion structure. Cans were then stored at either 22 or $41^{\circ} \mathrm{C}$ for 1 wk and samples were taken from each can and plated. It was observed that the sample that was stored at $41^{\circ} \mathrm{C}$ for 1 wk had much higher C. sporogenes counts $\left(1.1 \times 10^{6} \mathrm{cfu} / \mathrm{mL}\right)$ compared with the equivalent sample stored at $22^{\circ} \mathrm{C}$, which had little to no growth $(<10 \mathrm{cfu} / \mathrm{mL}$, Figure 3$)$. The high counts observed in the $41^{\circ} \mathrm{C}$ samples therefore appear to be due to a combination of both the broken emulsion and the optimal incubation temperature for $C$. sporogenes growth. For the $22^{\circ} \mathrm{C}$ samples, it appears that breaking the emulsion alone did not have a large effect on $C$. sporogenes growth. It is likely that both factors play a role in bacterial growth. This experiment was a small-scale secondary experiment, and therefore it is suggested that further analysis be performed using a broader experimental design to fully determine the extent of interaction.

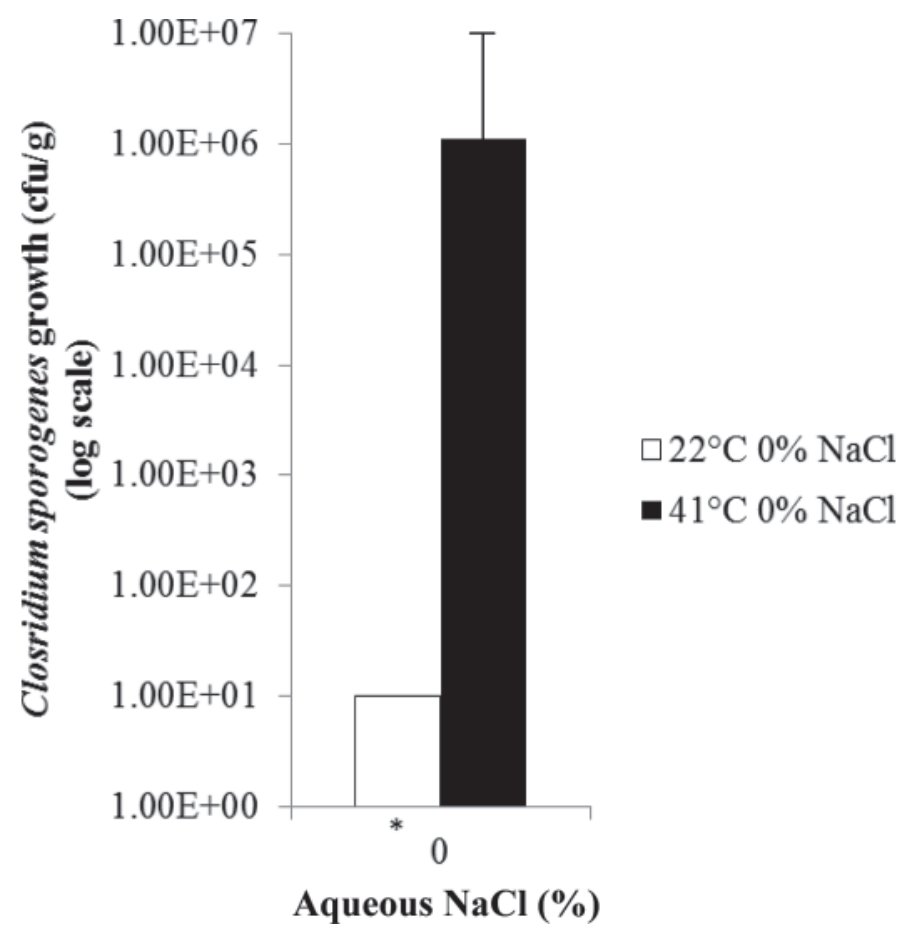

Figure 3. Effects of breaking the butter emulsion versus optimal incubation temperature. Both samples were heated at $41^{\circ} \mathrm{C}$ for $18 \mathrm{~h}$ to break the emulsion and then stored at either 22 or $41^{\circ} \mathrm{C}$ for $1 \mathrm{wk}$. Columns marked with an asterisk indicate no growth at the limit of detection based on the dilution plated; the reported value for the col$\mathrm{umn}$ is $<10 \mathrm{cfu} / \mathrm{g}$.

\section{Butter Aqueous Droplet Size}

Qualitative analysis of confocal images was performed on experimental (batch) and commercially (continuous) processed samples $(\mathrm{n}=6$; Figure 4$)$. A large discrepancy between the batch- and continuousprocessed samples was not apparent, based on visual observation; this was supported by the quantitative ImageJ software analysis. Average droplet diameter for batch-churned butter produced in the laboratory was $5.46 \mu \mathrm{m}$; whereas average droplet diameter for butter produced through continuous processing by a local dairy manufacturer was $5.44 \mu \mathrm{m}$ (Figure 4). The onesided $t$-test $P$-value for comparison of mean area was 0.459; therefore, no significant difference exists between average adjusted droplet diameters of batch-churned butter produced by the BYU research team and butter produced by a commercial facility through continuous processing.

The droplet sizes of the batch-churned butter were generally observed to be small enough to inhibit microbial growth. As mentioned previously, the threshold for support of bacterial growth is a diameter $>20 \mu \mathrm{m}$ (Wehr and Frank, 2004). Therefore, by counting the number of droplets larger than $20 \mu \mathrm{m}$ and calculating the average diameter of those droplets, it is possible to obtain another indicator of bacterial growth potential. Image analysis of batch-churned butter resulted in an average of $36.5 \pm 9.3$ droplets per microscopic field with a diameter $>20 \mu \mathrm{m}$ and an average diameter of those droplets at $57.4 \mu \mathrm{m}$. Continuous-processed butter had an average of $38 \pm 10.9$ droplets per field with a diameter $>20 \mu \mathrm{m}$ and an average diameter of those droplets at $52.1 \mu \mathrm{m}$. The $t$-test comparisons of both droplet number and average large droplet size resulted in one-tailed $P$-values of 0.40 and 0.180 , respectively. Therefore, no significant difference was observed between batch- and continuous-processed butter with regard to the number of droplets per field $>20 \mu \mathrm{m}$ in diameter and the average diameter of those droplets. This provides increased evidence of the similarity in structure of butter samples produced by these 2 processing methods, and confirms the ability to make comparisons between samples produced by these 2 methods.

\section{Sensory Evaluation}

The primary objective of the sensory evaluation was to determine what salt level was considered optimal, and, more specifically, to determine if salt levels that appeared to be inhibitory to C. sporogenes were acceptable to consumers. Therefore, higher than typical salt levels, which were proposed to be more inhibitory, were also evaluated. The mean hedonic score ranges 
(A)

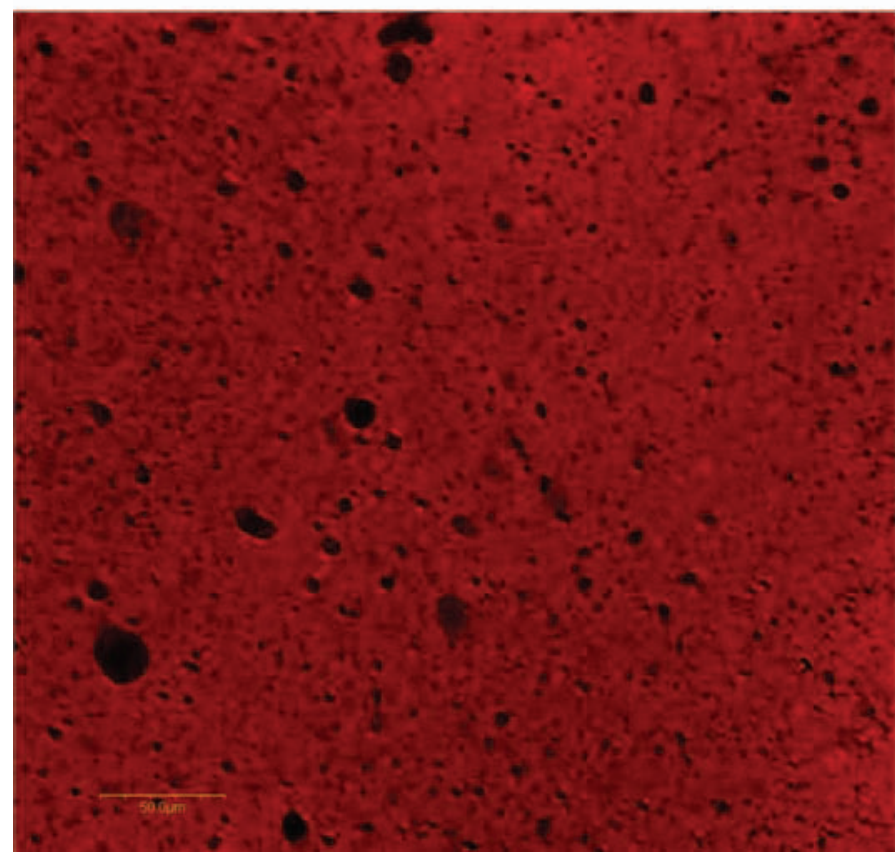

(B)

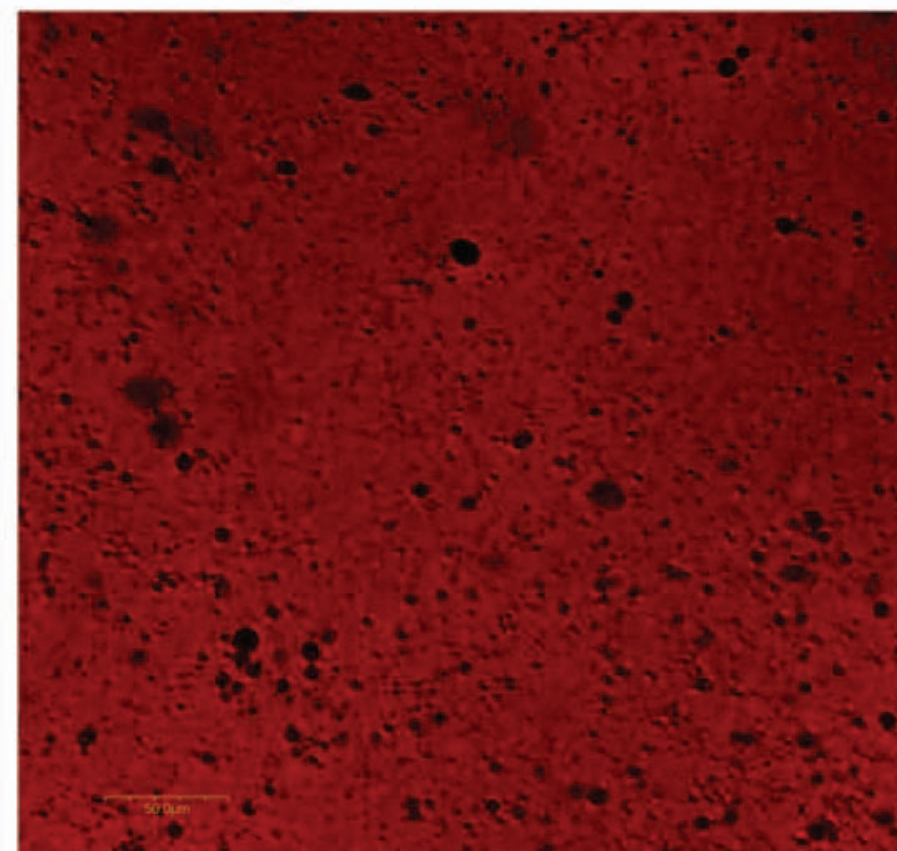

Figure 4. Confocal microscopy images of butter stained with Nile red dye (Sigma-Aldrich, St. Louis, MO); lipid fraction is seen as the red (dark gray) continuous phase and aqueous droplets are seen as dark black circles. (A) Butter produced in laboratory by batch process; average corrected droplet diameter $=5.46 \mu \mathrm{m}$. (B) Butter produced by a commercial continuous process; average corrected droplet diameter $=5.44 \mu \mathrm{m}$. The $t$-test analysis demonstrates no significant difference between mean average relative droplet area for batch process and continuous processed butter. Color version available in the online PDF.

were 5.68 to 7.40 for overall acceptability, 6.96 to 7.53 for appearance, 5.21 to 7.38 for overall flavor, and 3.87 to 7.06 for salt flavor. Consistently, $1.6 \%$ salt and $0.8 \%$ salt had the highest hedonic score values and neither was significantly different from the other (Table 4). An ideality question for level of salt was also included to determine what salt concentrations were considered optimal to consumers. Ideal concentration was determined to be $1.6 \%$ for salt, whereas $0.8 \%$ salt was considered not salty enough and $2.4,3.2$, and $4.0 \%$ salt were all

Table 4. Mean acceptance, level of salt ideality, and rank sum scores of butter with varying salt amounts ${ }^{1}$

\begin{tabular}{|c|c|c|c|c|c|c|}
\hline \multirow[b]{2}{*}{ Item } & \multicolumn{5}{|c|}{$\mathrm{NaCl}$ Added } & \multirow{2}{*}{$\begin{array}{c}\text { Critical } \\
\text { value }\end{array}$} \\
\hline & $0.8 \%$ & $1.6 \%$ & $2.4 \%$ & $3.2 \%$ & $4.0 \%$ & \\
\hline Overall & $7.32^{\mathrm{a}}$ & $7.40^{\mathrm{a}}$ & $6.77^{\mathrm{ab}}$ & $6.57^{\mathrm{b}}$ & $5.68^{\mathrm{c}}$ & 0.695 \\
\hline Appearance & $7.53^{\mathrm{a}}$ & $7.47^{\mathrm{a}}$ & $7.45^{\mathrm{a}}$ & $7.13^{\mathrm{ab}}$ & $6.96^{\mathrm{b}}$ & 0.40 \\
\hline Overall flavor & $7.38^{\mathrm{a}}$ & $7.36^{\mathrm{a}}$ & $6.43^{\mathrm{b}}$ & $6.40^{\mathrm{b}}$ & $5.21^{\mathrm{c}}$ & 0.79 \\
\hline Salt flavor & $7.06^{\mathrm{a}}$ & $6.89^{\mathrm{a}}$ & $5.66^{\mathrm{b}}$ & $5.04^{\mathrm{b}}$ & $3.87^{\mathrm{c}}$ & 1.049 \\
\hline Level of salt ideality (ideal $=3.00$ ) & $2.74^{2}$ & $2.96^{3}$ & $3.77^{4}$ & $4.00^{4}$ & $4.49^{4}$ & $\mathrm{NA}^{5}$ \\
\hline Ranking (rank sum) & $119^{\mathrm{a}}$ & $116^{\mathrm{a}}$ & $147^{\mathrm{ab}}$ & $185^{\mathrm{bc}}$ & $228^{\mathrm{c}}$ & 44.4 \\
\hline
\end{tabular}

${ }^{\mathrm{a}-\mathrm{C} C o m m o n}$ superscripts in the same row indicate no significant difference $(P>0.05)$. Significant difference is determined based on a separation of mean values by Tukey's critical value (far right column) or more.

${ }^{1}$ Acceptance scores range from 1 to 9,1 being least acceptable and 9 being most acceptable. Ideality values range from 1 to 5 , with 3 being ideal, 1 being too low and 5 being too high. Rank sum values are a total sum of the rank value (1-5) that panelists assigned to each butter sample, with 1 being most liked and 5 being least liked. Therefore, the butter with the lowest rank sum value was most preferred by panelists and the butter sample with the highest rank sum value was least preferred.

${ }^{2}$ Too little salt.

${ }^{3}$ Just about right.

${ }^{4}$ Too salty.

${ }^{5} \mathrm{NA}=$ not applicable. 
considered too salty. Rank sum values were determined by calculating the total of all rank values and it was observed that 1.6, 0.8 , and $2.4 \%$ had the lowest rank sum values respectively; however, none of the 3 were significantly different from another. Therefore 1.6, 0.8, and $2.4 \%$ were the most preferred samples with no significant difference among them.

It is not surprising that butter samples with $0.8,1.6$, and $2.4 \% \mathrm{NaCl}$ were the most preferred by consumers, as typical salted butter contains between 1.5 and $2 \%$ $\mathrm{NaCl}$, which would be around 9.4 to $12.5 \% \mathrm{NaCl}$ of the aqueous phase (Voysey et al., 2009). Whereas butter with $2.4 \% \mathrm{NaCl}$ was inhibitory, it was still not sufficient to entirely eliminate C. sporogenes growth.

\section{CONCLUSIONS}

The preparation and canning of butter in a home process setting is strongly discouraged due to the heating of the butter to ensure a proper vacuum seal. This heating step destroys butter emulsion integrity, removing that specific hurdle and, thereby, increasing the potential for $C$. botulinum growth and toxin production. Commercially canned butter samples may also potentially undergo heat abuse through transport in a hot truck, storage in a hot warehouse, or abusive consumer storage practices. Food products must remain safe, even if exposed to conditions resulting in abuse and product damage. Due to the possibility of heat abuse, which could result in growth of $C$. botulinum and toxin production, it is recommended that further studies be conducted on commercially canned butter to ensure its safety even under potentially adverse storage conditions. With further study, regulatory agencies could provide additional direction for safe production of a canned butter product.

\section{REFERENCES}

Abramoff, M. D., P. J. Magelhaes, and S. J. Ram. 2004. Image processing with ImageJ. Biophotonics Int. 11:36-42.

Andress, E., and B. Nummer. 2006. Should I use directions for canning butter at home that I see on the internet? Accessed Feb. 4, 2010. http://nchfp.uga.edu/questions/FAQ_canning.html\#33.

AOAC International. 2003. Official Methods of Analysis. 17th ed. AOAC International, Gaithersburg, MD.

Britten, M., S. Lamothe, and G. Robitaille. 2008. Effect of cream treatment on phospholipids and protein recovery in butter-making process. Int. J. Food Sci. Technol. 43:651-657.

Bull, M. K., S. A. Olivier, R. J. van Diepenbeek, F. Kormelink, and B. Chapman. 2009. Synergistic inactivation of spores of proteolytic Clostridium botulinum strains by high pressure and heat is strain and product dependent. Appl. Environ. Microbiol. 75:434-445.

Charley, H., and C. Weaver. 1998. Foods: A Scientific Approach. Merrill, Upper Saddle River, NJ.

Cole, W. R., and S. Oh. 2003. US Food and Drug Administration requirements for the processing of low-acid canned foods. Food Sci. Biotechnol. 12:705-720.
Dasgupta, A. P., and R. R. Hull. 1989. Late blowing of Swiss cheeseIncidence of Clostridium tyrobutyricum in manufacturing milk. Aust. J. Dairy Technol. 44:82-87.

FDA (Food and Drug Administration). 2010. Acidified and lowacid canned foods. Accessed Jan. 4, 2011. http://www.fda.gov/ Food/GuidanceComplianceRegulatoryInformation/Guidance Documents/AcidifiedandLow-AcidCannedFoods/default.htm.

Fennema, O. R. 1996. Food Chemistry. Marcel Dekker, New York, NY. Hirsch, A., and E. Grinstead. 1954. Methods for the growth and enumeration of anaerobic spore formers from cheese, with observations on the effect of nisin. J. Dairy Res. 21:101-110.

Klijn, N., F. F. J. Nieuwenhof, J. D. Hollwerf, C. B. Vanderwaals, and A. H. Weerkamp. 1995. Identification of Clostridium tyrobutyricum as the causative agent of late blowing in cheese by species-specific PCR amplification. Appl. Environ. Microbiol. 61:2919-2924.

Le Bourhis, A. G., J. Dore, J. Carlier, J. Chamba, M. Popoff, and J. Tholozan. 2007. Contribution of C. beijerinckii and C. sporogenes in association with $C$. tyrobutyricum to the butyric fermentation in Emmental type cheese. Int. J. Food Microbiol. 113:154-163.

Leistner, L. 2000. Basic aspects of food preservation by hurdle technology. Int. J. Food Microbiol. 55:181-186.

Leistner, L., and L. G. M. Gorris. 1995. Food preservation by hurdle technology. Trends Food Sci. Technol. 6:41-46.

Lund, B. M., T. C. Baird-Parker, and G. W. Gould. 2000. The Microbiological Safety and Quality of Food. Aspen Publishers, Gaithersburg, MD.

Mah, J. H., D. Kang, and J. Tang. 2008. Effects of minerals on sporulation and heat resistance of Clostridium sporogenes. Int. J. Food Microbiol. 128:385-389.

Nygaard, H., and O. Hostmark. 2008. Microbial inactivation during superheated steam drying of fish meal. Drying Technol. 26:222230.

Simjee, S. 2007. Foodborne Diseases. Humana Press, Totowa, NJ.

Slabbinck, B., B. De Baets, P. Dawyndt, and P. De Vos. 2008. Genuswide bacillus species identification through proper artificial neural network experiments on fatty acid profiles. Antonie van Leeuwenhoek 94:187-198.

Stone, H. 1985. Sensory Evaluation Practices. Academic Press, Orlando, FL.

Van Dalen, G. 2002. Determination of the water droplet size distribution of fat spreads using confocal scanning laser microscopy. J. Microsc. 208:116-133.

Verrips, C. T., D. Smid, and A. Kerkhof. 1980. The intrinsic microbial stability of water-in-oil emulsions. 2. Experimental. Eur. J. Appl. Microbiol. Biotechnol. 10:73-85.

Verrips, C. T., and J. Zaalberg. 1980. The intrinsic microbial stability of water-in-oil emulsions. 1. Theory. Eur. J. Appl. Microbiol. Biotechnol. 10:187-196.

Voysey, P. A., P. A. Anslow, K. J. Bridgwater, B. Lavender, and L. Watson. 2009. The effects of butter characteristics on the growth of Listeria monocytogenes. Int. J. Dairy Technol. 62:326-330.

Wehr, H. M., and J. F. Frank. 2004. Standard Methods for the Examination of Dairy Products. 17th ed. American Public Health Association, Washington, DC.

Wilson, P. D. G., T. F. Brocklehurst, S. Arino, D. Thuault, M. Jakobsen, M. Lange, J. Farkas, J. W. T. Wimpenny, and J. F. Van Impe. 2002. Modelling microbial growth in structured foods: Towards a unified approach. Int. J. Food Microbiol. 73:275-289.

Wood, F. W., M. F. Murphy, and W. L. Dunkley. 1975. Influence of elevated polyunsaturated fatty-acids on processing and physicalproperties of butter. J. Dairy Sci. 58:839-845.

Yang, W. W., E. N. Crow-Willard, and A. Ponce. 2009. Production and characterization of pure clostridium spore suspensions. J. Appl. Microbiol. 106:27-33.

Yilmaz, S. O. 2009. Identification of microflora in butter samples from turkey by using the microbial identification system. Asian J. Chem. 21:3257-3262. 